\title{
25 Research Soure \\ Relationship between health literacy and fast food consumption: A population-based study from southern Iran
}

Azam Namdar ( $\square$ hila421@yahoo.com )

Fasa University of Medical Science https://orcid.org/0000-0002-5245-2901

Mohammad Mehdi Naghizadeh

Fasa University of Medical Science

Ali Montazeri ( $\square$ montazeri@acecr.ac.ir)

Iranian Institute for Health Sciences Research

Marziyeh Zamani

Jahrom University of Medical Science

Research article

Keywords: Adults, Fast food, Health literacy, Iran, reading skills, decision-making

Posted Date: August 13th, 2020

DOI: https://doi.org/10.21203/rs.3.rs-37135/v1

License: (a) (i) This work is licensed under a Creative Commons Attribution 4.0 International License.

Read Full License

Version of Record: A version of this preprint was published at BMC Public Health on April 20th, 2021. See the published version at https://doi.org/10.1186/s12889-021-10763-3. 


\section{Abstract}

Background: Having appropriate health literacy may affect the consumption of fast food. We aimed to evaluate the effect of health literacy on fast food consumption among the adult populations.

Methods: We evaluated health literacy and fast food consumption using an appropriate questionnaire in 421 adult participants with the age range of 18-65 years old in Fasa city, Fars Province, southern Iran. Two-step cluster sampling and, then, systematic sampling were performed. Data collection was done through demographic information questionnaire, checklist on fast food consumption, and the Health Literacy for Iranian Adults (HELIA) questionnaire. Data were harvested by face-to-face conversations. Population data across groups with/without fast food intake were compared.

Results: Most of our participants used fast food every few months (49.9\%). People with low or unstable income consumed more fast food than others $(P<0.05)$. Sandwich and hotdog were the most consumed fast food $(60.8 \%)$ and pizza was in the next step (34.9\%). Sausage and soda were the most seasoning food (66.7\%). Most of our participants used fast food as dinner (67.9\%) and along with their family $(72.2 \%)$, suggesting the institutionalized consumption of this type of food in the family. Fun was the most frequent reason for the use of fast food (66.5\%). Most of the participants completely knew about the raw materials for fast food and their adverse effects. Finally, we found that health literacy among those who used fast food was less than those who did not consumed fast food. This difference was also observed in the subscales of reading skills, critique, and decision-making.

Conclusions: It seems differences in health literacy and its components can affect fast food consumption. In addition, there was a negative relationship between health literacy and fast food consumption, which was also observed in reading skills, critique, and decision-making.

\section{Background}

With the advance of industry and technology and the changing lifestyle and eating habits of households, the food away from home consumption in restaurants and fast-food has become increasingly common and the demand for such foods is increasing and replaced by traditional methods (1).

Health literacy is the ability to acquire, process, and conceive basic health-related information and services (2). Based on the definition provided by World Health Organization (WHO), health literacy is a complex of social and cognitive abilities to acquire, understand, and apply health-related information for health promotion (3). It has been confirmed that people with higher levels of health literacy have more information about their health status (4).

Fast food is defined as a convenience food purchased in self-service or carry-out eating venues without wait service (5). This kind of food can induce several health problems such as body weight gain. In this regard, most people do not know about the harmful effects of this type of food (6). Despite severe adverse health effects, fast food consumption has increased gradually due to the increase in the number 
of women working, changes in the family structure, worldwide urbanization, long working hours, and rapid growth of fast food industries and restaurants (7).

Thus, it seems that fast food consumption is becoming a major public health problem worldwide. As such many governments are seeking to find out ways that could reduce fast food consumption. In this regard some investigators proposed that if we could increase health literacy among populations, then it might be possible to reduce fast food consumption much easier. However, the association between health literacy and fast food consumption is unclear and there is very limited published data from the Iran region on the topic. Thus, the present study was conducted to evaluate the relationship between health literacy and fast food consumption among the adult populations of Fasa located in south of Iran in 2018.

\section{Methods}

\section{Design}

The present cross-sectional study (descriptive-analytic) was conducted in 2018 on the adult population (aged 18-65 years old) in Fasa, Fars Province, Southern Iran. Before initiating the study, it was approved by the Ethics Committee of Fasa University of Medical Sciences (IR.FUMS.REC.2017.255).

\section{Sampling}

The research population was selected from the age range of 18-65 years old. Other inclusion criteria were residence in Fasa during the research period, belonging to the family visited, and being literate (i.e. knowing how to read and write). The sample size was determined using Cochran's formula. Based on this formula, the required size was estimated at 384 , which was then increased to 423 with the probability of $10 \%$ attrition.

The sampling method was stratified cluster sampling conducted in two steps. Since the population comprised those aged 18-65 years old residing in Fasa, clinics and health centers were considered as the cluster heads. In the first stage, by dividing the health centers, 11 regions ( 3 clinics and 8 health centers) were selected using stratified cluster sampling. In the next stage, systematic sampling was performed and, a list of households (as the basis for sampling) and the number of samples in each stratum were estimated.

\section{Instruments}

1. Health literacy: It was measured using the Health Literacy for Iranian Adults-HELIA (8). The HELIA measures five dimensions: "access" (items 1-6), "reading" (items 7-10), "understanding" (items 1117), "appraisal" (18-21), and "decision-making/behavioral intention" (items 22-33). Scores on HELIA are classified into four categories: inadequate and problematic (which together define "limited health literacy") and sufficient and excellent (which together define "desired health literacy"). Scores on the HELIA range from 0 to 100 that represent the following criteria: 0-50: inadequate, 50.1-66: 
problematic, 66.1-84: sufficient, and 84.1-100 excellent. The psychometric properties of the HELIA are well documented (8).

2. Fast food consumption: A checklist was specifically developed for in study that was used to collect data on fast food intake. By fast food, we meant different sandwiches; hamburgers, cheeseburgers, and other burgers; fried fish and shrimp; hot dog; meat or chicken steak; French fries; fried chicken; tacos (a Mexican dish); pizzas; and snacks, which are usually prepared in restaurants and outside the home. If fast food was consumed at least once a month, the person was considered to be a user; otherwise, he/she was considered as a non-user. Finally, consuming fast food less than once a week was called "little use", 1-2 times a week was called "moderate use", and more than twice a week was labeled as "excessive use" (9).

3. BMI was calculated using the weight in kilograms divided by the square of the height in meters $\left(\mathrm{kg} / \mathrm{m}^{2}\right)(10)$. Based on WHO classification, $\mathrm{BMI} \geq 25 \mathrm{~kg} / \mathrm{m}^{2}$ was considered as overweight and obese (11).

\section{Data analysis}

Data were expressed as mean, standard deviation (SD), frequency, and percentage. The Chi-squared test was used for group comparison (between with and without of fast food intake). The score for the HELIA was compared across the groups using the Welch-corrected t-test. Moreover, the confidence interval and odds ratio were calculated using logistic regression analysis. The significance level was set at $<0.05$ in all instances. The data were analyzed using IBM SPSS 24 (IBM SPSS CO., Armonk, NY).

\section{Results}

In all 421 participants were entered into the study. Of these 210 individuals were fast food uses and the remaining 211 were non-users. The mean age of participants was $37.3 \pm 11.5$ years. The mean age of fast food users was $36.2 \pm 11.9$ years and that of non-users was $38.3 \pm 11.1$ years $(p=0.056)$. The mean BMl was found to be $25.1 \pm 5.1 \mathrm{~kg} / \mathrm{m}^{2}$. The demographic characteristics of the study sample are presented in Table 1.

Based on the findings, 49 persons (11.6\%) had a fast food membership card. Different types of sandwiches and hot dog had the highest rate of intake $(60.8 \%, \mathrm{n}=256)$ and steak ranked the least $(3.8 \%$, $\mathrm{n}=16)$. Moreover, 249 people (82.9\%) consumed sauces with fast food and 281 (66.7\%) drank soft beverages with it. The motivation for fast food was enjoyment and fun for 280 people (66.5\%). Furthermore, $116(27.6 \%)$ consumed it, because they were busy and had little time to prepare food at home. Based on the definitions, 16 people (8.3\%) were excessive users, 295 (70.8\%) were low users, and the rest were moderate users. The detailed findings on pattern of fast food consumption are presented in Table 2.

The findings for HELIA are presented in Table 3. The mean health literacy score was $70.65(S D=22.20)$. In all $161(48.7 \%)$ of participants had limited health literacy (inadequate and problematic). 
The odds of fast food intake in the groups with problematic, sufficient, and excellent health literacy was 0.693 times $(p=0.253), 0.616$ times $(p=0.076)$, and 0.554 times $(p=0.034)$ compared to the group with inadequate literacy (Fig. 1).

Table 4 compares the mean HELIA scores of users and non-users. The results revealed that the mean HELIA score was significantly lower in users $(68.16 \pm 23.85)$ than non-users $(73.15 \pm 20.15),(p=0.021)$. The same was true for reading, and decision-making $(p<0.001$, and $p=0.018$, respectively).

Finally the results obtained from logistic regression analysis (after controlling for confounding variables) showed that by 1 score increase in health literacy, the odds of fast food intake was reduced by $1 \%$ (OR = $0.990,95 \% \mathrm{Cl}=0.981-0.999)$. This relationship was also observed for the ability of reading $(\mathrm{OR}=0.985$, $95 \% \mathrm{Cl}=0.975-0.993)$ and decision-making $(\mathrm{OR}=0.986,95 \% \mathrm{Cl}=0.072-0.999)$. The results for both unadjusted and adjusted odds ratio for fast food intake are shown in Table 5.

\section{Discussion}

The present study examined the relationship between health literacy and food consumption among the adult populations. The findings showed that about $50 \%$ of the study participants were using fast food regularly. They used fast food as dinner and with their family, suggesting the institutionalized consumption of this type of food in the family and $11.6 \%$ of they had a membership card for fast food restaurants, indicating a tendency for the repeated intake of fast food in the future. In addition, peoples with low or unstable income used more fast foods than other peoples, of course cheap fast foods such as cutlet and falafel sandwiches.

Developing countries are experiencing major changes in their nutrition as a result of a significant increase in per capita income $(12,13)$ and the process of eating has shifted toward food away from home and spend an increasing share of their food expenditures on food away from home (14) also worldwide, consumption food away from home has grown significantly in the past two decade $(15,16)$. There is also evidence in Iran that the nutritional transition is accelerating towards an increased consumption of fast food, followed by an increase in the prevalence of chronic diseases (17).

According to our findings, health literacy in those who used fast food was less than those who did not. This difference also was seen in the subscales of reading skills, and decision-making. Finally, we found a significantly negative association between health literacy and subscales of reading skills and decisionmaking with the consumption of fast foods. The findings from this study confirm that health literacy has a close relationship with health-related behavior such as fast food consumption. In addition the findings confirm the fact that nutrition literacy as specific health literacy reflects the ability to access, interpret, and use nutrition-related information $(18,19)$.

Given the importance of health literacy and its relationship with fast food consumption, it seems there are limited studies on the topic. However, several studies have demonstrated the association between fast food consumption and obesity as a public health problem $(20,21)$. 
Therefore, we compare the results of some related studies with our findings. In a recent study on the relationship between health literacy and nutritional practice in high school adolescents of Tehran, capital of Iran, $74.5 \%$ of the adolescents had inadequate and problematic health literacy, and $68 \%$ had unsatisfactory nutritional practice. In addition, similar to our findings, nutritional practice was improved by increasing health literacy (22).

We found that reading skills and decision-making were important in health literacy and had some associations with fast food consumption. Linnebur also showed that limited health literacy was associated with students' inability to read and understand food labels (23). Perhaps this also true for the general population especially for people with lower education level. Fast food has several health-related adverse and harmful effects, which are comparable to cigarette smoking. Consistent with the present work, Panahi et al. evaluated the relationship of health literacy with knowledge and attitude toward the harms of cigarette smoking among university students and found a significantly direct relationship between the knowledge and attitudes toward smoking hazards (24).

Our study had several strengths. The main strength was the focus on health literacy and its relationship with fast food consumption that received less attention. The sampling method was another strength of this study since it was a population-based study. In addition we used a well developed instrument for health literacy that covers public health related items. Finally the completion of the questionnaires through structured interview rather than self-reported was another strength.

The study however had some limitations. One limitation of this study was the use of a general health literacy that is inadequate for studies on nutrition because it does not assess nutrition literacy. Therefore we recommend the further investigations use Nutrition Literacy Assessment Instrument is requires (18). Secondly since our study was cross-sectional, we could not establish a causal inference. Thirdly the study participants were from the southern region of Iran only, and so our results could not represent other regions of the country, therefore, more studies, based on large national representative samples are needed to better understand the relationship between health literacy and fast food intake in order to implement appropriate interventions. Educational interventions are recommended to improve health literacy with emphasis on increasing nutrition literacy and survey its effect on healthy food choices.

\section{Conclusion}

The finding from the current study showed that differences in health literacy might affect fast food consumption. Reading skills and decision-making (behavioral intentions) seem are very relevant to fast food consumption.

\section{Declarations}

\section{Ethics approval and consent to participate}


The ethics committee of Fasa University of Medical Sciences (Code: IR.FUMS.REC.2017.255) approved this study. All participant gave written consent to take part in the study.

\section{Consent to publish}

Not applicable.

\section{Availability of data and materials}

The data are available from the corresponding authors.

\section{Competing interests}

The authors declare that they have no conflict of interests.

\section{Funding}

The Fasa University of Medical Sciences funded the study.

\section{Authors' Contributions}

The idea of this study was initiated by AN and AM. AN contributed to design, management of the study, data gathering and writing of the manuscript. AM participated to study design and writing of the manuscript, edition and revision. MMN participated in the design of the study and performed the statistical analysis. MZ contributed in design and writing of the manuscript. All authors read and approved the final manuscript.

\section{Acknowledgements}

We have to express our thanks to the research deputy Fasa University of Medical Sciences as well as appreciate all loved ones who those who participated in this research project or otherwise helped us conduct this study.

\section{Abbreviations}

HELIA: Health Literacy for Iranian Adults; SD: standard deviation.

\section{References}

1. Farazmand $\mathrm{H}$, Hallafi $\mathrm{H}$. The Demand for Away from Home Food in Iranian Households: An Application of Box-Cox Double Hurdle Model. Economic Modeling. 2016;9(32):65-85.

2. Truman E, Bischoff M, Elliott C. Which literacy for health promotion: health, food, nutrition or media? Health promotion international. 2019. 
3. Yusefi A, Ebrahim Z, Bastani P, Najibi M, Radinmanesh M, Mehrtak M. Health literacy status and its relationship with quality of life among nurses in teaching hospitals of Shiraz University Of Medical Sciences. Iranian journal of nursing and midwifery research. 2019;24(1):73.

4. Walker J, Pepa C, Gerard PS. Assessing the health literacy levels of patients using selected hospital services. Clinical Nurse Specialist. 2010;24(1):31-7.

5. Mohammadbeigi A, Asgarian A, Moshir E, Heidari H, Afrashteh S, Khazaei S, et al. Fast food consumption and overweight/obesity prevalence in students and its association with general and abdominal obesity. Journal of preventive medicine and hygiene. 2018;59(3):E236.

6. Burgoine T, Sarkar C, Webster CJ, Monsivais P. Examining the interaction of fast-food outlet exposure and income on diet and obesity: evidence from 51,361 UK Biobank participants. International Journal of Behavioral Nutrition and Physical Activity. 2018;15(1):71.

7. An R. Fast-food and full-service restaurant consumption and daily energy and nutrient intakes in US adults. European journal of clinical nutrition. 2016;70(1):97.

8. Montazeri A, Tavousi M, Rakhshani F, Azin SA, Jahangiri K, Ebadi M, et al. Health Literacy for Iranian Adults (HELIA): development and psychometric properties. Payesh (Health Monitor). 2014;13(5):58999.

9. Pereira MA, Kartashov Al, Ebbeling CB, Van Horn L, Slattery ML, Jacobs Jr DR, et al. Fast-food habits, weight gain, and insulin resistance (the CARDIA study): 15-year prospective analysis. The lancet. 2005;365(9453):36-42.

10. Organization WH. Obesity: preventing and managing the global epidemic: World Health Organization; 2000.

11. Ulijaszek SJ. Obesity: Preventing and Managing the Global Epidemic. Report of a WHO Consultation. WHO Technical Report Series 894. Pp. 252.(World Health Organization, Geneva, 2000.) SFr 56.00, ISBN 92-4-120894-5, paperback. Journal of biosocial science. 2003;35(4):624-5.

12. Chang $\mathrm{H}-\mathrm{H}$, Yen ST. Off-farm employment and food expenditures at home and away from home. European Review of Agricultural Economics. 2010;37(4):523-51.

13. Akbay C, Tiryaki GY, Gul A. Consumer characteristics influencing fast food consumption in Turkey. Food control. 2007;18(8):904-13.

14. Bai J, Wahl TI, Lohmar BT, Huang J. Food away from home in Beijing: Effects of wealth, time and "free" meals. China Economic Review. 2010;21(3):432-41.

15. Mancino L, Todd J, Lin B-H. Separating what we eat from where: measuring the effect of food away from home on diet quality. Food Policy. 2009;34(6):557-62.

16. Liu M. Food Expenditures away from Home by Type of Meal and by Facility. 2011.

17. Ghassemi H, Harrison G, Mohammad K. An accelerated nutrition transition in Iran. Public health nutrition. 2002;5(1a):149-55.

18. Carbone ET, Zoellner JM. Nutrition and health literacy: a systematic review to inform nutrition research and practice. Journal of the Academy of Nutrition and Dietetics. 2012;112(2):254-65. 
19. Watson WL, Chapman K, King L, Kelly B, Hughes C, Yu Louie JC, et al. How well do Australian shoppers understand energy terms on food labels? Public health nutrition. 2013;16(3):409-17.

20. Fung C, Mclsaac J-LD, Kuhle S, Kirk SF, Veugelers PJ. The impact of a population-level school food and nutrition policy on dietary intake and body weights of Canadian children. Preventive medicine. 2013;57(6):934-40.

21. Dunn RA, Sharkey JR, Horel S. The effect of fast-food availability on fast-food consumption and obesity among rural residents: an analysis by race/ethnicity. Economics \& Human Biology. 2012;10(1):1-13.

22. Saeedy Golluche F, Jalili Z, Tavakoli R. The Study of Relationship Between Health Literacy and Nutritional Practice in High School Adolescents in Tehran. Iranian Journal of Health Education and Health Promotion. 2017;5(3):224-30.

23. Linnebur LA, Linnebur SA. Self-administered assessment of health literacy in adolescents using the newest vital sign. Health promotion practice. 2018;19(1):119-24.

24. Panahi R, Ramezankhani A, Tavousi M, Koosehloo A, Niknami S. Relationship of health literacy with knowledge and attitude toward the harms of cigarette smoking among University Students. J Educ Community Health. 2017;3(4):38-44.

\section{Tables}

Table 1. Demographic variables and fast food consumption in the study sample 


\begin{tabular}{|c|c|c|c|c|}
\hline & $\begin{array}{l}\text { All }(n= \\
421)\end{array}$ & $\begin{array}{l}\text { Non-users* }(n= \\
210)\end{array}$ & $\begin{array}{l}\text { Users }(n= \\
211)\end{array}$ & \\
\hline & No. (\%) & No. (\%) & No. (\%) & $\mathbf{P}$ \\
\hline Gender & & & & $0.365^{\star \star}$ \\
\hline Female & $294(69.8)$ & $151(71.9)$ & $143(67.8)$ & \\
\hline Male & $127(30.2)$ & $59(28.1)$ & $68(32.2)$ & \\
\hline Marital status & & & & 0.554 \\
\hline Single & 105 (24.9) & $55(26.2)$ & $50(23.7)$ & \\
\hline Married & $316(75.1)$ & $155(73.8)$ & $161(76.3)$ & \\
\hline Education & & & & 0.918 \\
\hline $\begin{array}{l}\text { < Secondary } \\
\text { education }\end{array}$ & 77 (18.3) & $38(18.1)$ & 39 (18.5) & \\
\hline $\begin{array}{l}\geq \text { Secondary } \\
\text { education }\end{array}$ & 344 (81.7) & $172(81.9)$ & $172(81.5)$ & \\
\hline Income & & & & 0.023 \\
\hline$<\operatorname{IRR} 1,500,000$ & $308(59.8)$ & $145(69.4)$ & $163(79.1)$ & \\
\hline$>\operatorname{IRR} 1,500,000$ & $107(20.8)$ & $64(30.6)$ & $43(20.9)$ & \\
\hline \multicolumn{5}{|l|}{ BMI $\left(\mathrm{kg} / \mathrm{m}^{2}\right)$} \\
\hline$<25$ & $223(53.0)$ & $116(55.2)$ & $107(50.7)$ & 0.325 \\
\hline$\geq 25$ & $198(47.0)$ & $94(44.8)$ & $104(49.3)$ & \\
\hline \multicolumn{5}{|l|}{ Age } \\
\hline Mean (SD) & $37.3(11.5)$ & $38.3(11.1)$ & 36.2 (11.9) & $0.056^{\star \star \star}$ \\
\hline
\end{tabular}

* Fast food consumption less than once a month.

** Derived from Chi-square.

$\star \star \star$ Derived from t-test.

Table 2. Pattern of fast food consumption in the study sample 


\begin{tabular}{|c|c|c|c|}
\hline \multicolumn{2}{|l|}{ Variable } & No & $\%$ \\
\hline \multirow[t]{4}{*}{ Fast food consumption frequency } & More than twice a week & 16 & 3.8 \\
\hline & 1-2 times a week & 107 & 25.4 \\
\hline & Once or twice a month & 88 & 20.9 \\
\hline & Less than once a month & 210 & 49.9 \\
\hline \multirow[t]{2}{*}{ Membership card } & Yes & 49 & 11.6 \\
\hline & No & 372 & 88.4 \\
\hline \multirow[t]{2}{*}{ Types of sandwich and hot dog } & Yes & 256 & 60.8 \\
\hline & No & 165 & 39.2 \\
\hline \multirow[t]{2}{*}{ Pizza } & Yes & 147 & 34.9 \\
\hline & No & 274 & 65.1 \\
\hline \multirow[t]{2}{*}{ Other (snacks, fried foods...) } & Yes & 80 & 19.0 \\
\hline & No & 341 & 81.0 \\
\hline \multirow[t]{7}{*}{ Popularity } & $\begin{array}{l}\text { Any types of } \\
\text { sandwiches }\end{array}$ & 178 & 42.3 \\
\hline & Hot dog & 4 & 1.0 \\
\hline & Pizza & 114 & 27.1 \\
\hline & French fries & 38 & 9.0 \\
\hline & Steak & 16 & 3.8 \\
\hline & Fried chicken & 31 & 7.4 \\
\hline & Fried fish and shrimp & 40 & 9.5 \\
\hline \multirow[t]{2}{*}{ Sauces consumption } & Yes & 349 & 82.9 \\
\hline & No & 72 & 17.1 \\
\hline \multirow[t]{2}{*}{ Soft drinks } & Yes & 281 & 66.7 \\
\hline & No & 140 & 33.3 \\
\hline \multirow[t]{4}{*}{ Meal } & Breakfast & 1 & 0.2 \\
\hline & Lunch & 113 & 26.8 \\
\hline & Dinner & 286 & 67.9 \\
\hline & Supper & 21 & 5.0 \\
\hline
\end{tabular}




\begin{tabular}{|c|c|c|c|}
\hline \multirow[t]{3}{*}{ Companions } & Family & 304 & 72.2 \\
\hline & Friends & 96 & 22.8 \\
\hline & Alone & 21 & 5.0 \\
\hline \multirow{2}{*}{$\begin{array}{l}\text { Motivation: Enjoyment and fun for fast food } \\
\text { consumption }\end{array}$} & Yes & 280 & 66.5 \\
\hline & No & 141 & 33.5 \\
\hline \multirow[t]{2}{*}{ Motivation: Ease of access for fast food consumption } & Yes & 36 & 8.6 \\
\hline & No & 385 & 91.4 \\
\hline \multirow[t]{2}{*}{ Busy and had little time to prepare food at home } & Yes & 116 & 27.6 \\
\hline & No & 305 & 72.4 \\
\hline \multirow[t]{2}{*}{ Place of use } & Outside (restaurant) & 233 & 55.3 \\
\hline & Home & 188 & 44.7 \\
\hline \multirow[t]{2}{*}{ Aware of the fast food ingredients } & Yes & 292 & 69.4 \\
\hline & No & 129 & 30.6 \\
\hline \multirow[t]{3}{*}{ Priority factors in choosing fast food } & Hygiene & 321 & 76.2 \\
\hline & Diversity & 90 & 21.4 \\
\hline & Price & 10 & 2.4 \\
\hline \multirow[t]{2}{*}{ Aware of the harmfulness of fast food } & Yes & 381 & 90.5 \\
\hline & No & 40 & 9.5 \\
\hline
\end{tabular}

Table 3. Health literacy score and levels

\begin{tabular}{|llllll|}
\hline & & Inadequate & Problematic & Sufficient & Excellent \\
\hline Mean (SD) & No. (\%) & No. (\%) & No. (\%) & No. (\%) \\
\hline Access & $66.08(21.51)$ & $115(27.3)$ & $72(17.1)$ & $154(36.6)$ & $80(19.0)$ \\
\hline Understanding & $64.65(18.33)$ & $38(9.0)$ & $55(13.1)$ & $135(32.1)$ & $193(45.8)$ \\
\hline Appraisal & $68.07(17.04)$ & $73(17.3)$ & $93(22.1)$ & $179(42.5)$ & $76(18.1)$ \\
\hline Decision making & $69.85(15.27)$ & $42(10.0)$ & $119(28.3)$ & $182(43.2)$ & $78(18.5)$ \\
\hline Total score & $70.65(22.20)$ & $92(21.9)$ & $69(16.4)$ & $136(32.3)$ & $124(29.5)$ \\
\hline
\end{tabular}


Table 4. Effects of health literacy on fast-food consumption

\begin{tabular}{|llll|}
\hline & Users & Non-users & \\
\hline & Mean (SD) & Mean (SD) & P \\
\hline Reading & $62.46(22.10)$ & $69.72(20.30)$ & $<0.001$ \\
\hline Access & $77.08(19.95)$ & $80.22(16.44)$ & 0.089 \\
\hline Understanding & $64.81(22.94)$ & $64.43(20.03)$ & 0.855 \\
\hline Appraisal & $66.36(17.98)$ & $69.78(15.89)$ & 0.111 \\
\hline Decision making & $67.96(16.21)$ & $71.75(14.04)$ & 0.018 \\
\hline Total score & $68.16(23.85)$ & $73.15(20.15)$ & 0.026 \\
\hline
\end{tabular}

Table 5. The association between health literacy and fast food intake obtained from logistic regression analysis

\begin{tabular}{|lllll|}
\hline & Univariate analysis & \multicolumn{3}{l|}{ Adjusted analysis* } \\
\hline & OR $(95 \% \mathrm{Cl})$ & $\mathbf{P}$ & OR $(95 \% \mathrm{Cl})$ & $\mathrm{P}$ \\
\hline Reading & $0.984(0.975-0.993)$ & 0.001 & $0.985(0.975-0.995)$ & 0.004 \\
\hline Access & $0.991(0.980-1.001)$ & 0.080 & $0.992(0.981-1.004)$ & 0.191 \\
\hline Understanding & $1.001(0.992-1.010)$ & 0.858 & $1.001(0.992-1.011)$ & 0.781 \\
\hline Appraisal & $0.988(0.977-0.999)$ & 0.040 & $0.991(0.980-1.004)$ & 0.166 \\
\hline Decision making & $0.984(0.971-0.996)$ & 0.011 & $0.986(0.972-0.999)$ & 0.049 \\
\hline Total score & $0.990(0.981-0.998)$ & 0.022 & $0.990(0.981-0.999)$ & 0.045 \\
\hline
\end{tabular}

* Adjusted for age, gender, education, income and BMI

\section{Figures}




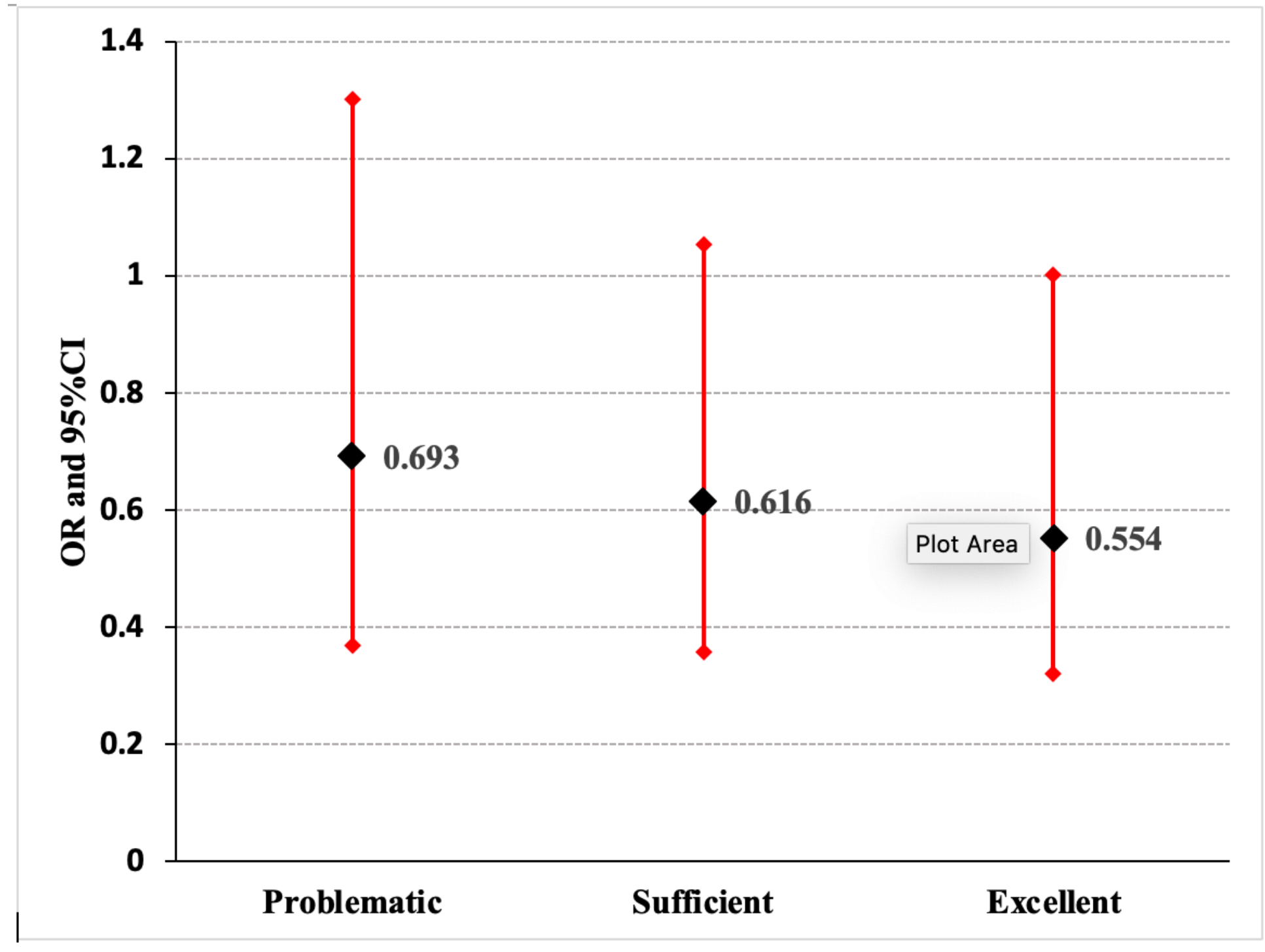

Figure 1

Odds of using fast food

\section{Supplementary Files}

This is a list of supplementary files associated with this preprint. Click to download.

- checklist1.doc.docx 